John G. Gunnell

University of California

\title{
Political Concepts and the Concept of the Political
}

\begin{abstract}
Although concepts are typically assumed to be at the core of both the language of politics and the language of political inquiry, the meaning of "concept" has remained notoriously vague. In everyday usage, prominent elements of philosophy, and the literature of political science and political theory, concepts are, however, primarily assumed to be mental phenomena that are expressed in words and actions. This assumption has been challenged by Ludwig Wittgenstein, Gilbert Ryle, and a variety of contemporary philosophers who claim that human thought is primarily linguistic. This suggests that concepts are best understood as forms of linguistic usage. The concept-word "politics" refers to a culturally and historically variable category of social phenomena, and it is a mistake to assume that the phrase "the political" designates a theoretical concept.
\end{abstract}

Keywords: concept, politics, mentalism, words, Wittgenstein

\section{Introduction}

Political Concepts: A Critical Lexicon is a recent multi-disciplinary web-based journal sponsored by several major United States universities. It is devoted to entries focusing on "a single concept with the express intention of resituating it in the field of political discourse by addressing what has remained unquestioned or untaught in that concept." The journal, however, explicitly states that it "does not predetermine what does or does not count as a political concept." This is only one example of a general failure to engage thoroughly the issue of the nature of concepts and of the circumvention of the issue of what is distinctive about political concepts.

While there are few words in the vocabularies of social theory and social science that appear more frequently than "concept," there are also few words that are more amorphously, elliptically, diversely, and unreflectively used. The ontology of concepts, that is, what kinds of things they are, has been hotly debated 
among some philosophers, but there is little consensus and often a lack of clarity about the use of the word "concept." What tends to predominate, and what has been passed on to social scientists by philosophers, as well as by our everyday manner of speaking, is the image of concepts as mental phenomena, which are expressed in language and action. This mentalistic image and its implications require careful scrutiny.

\section{The Mind-First Attitude}

There is little need, and it is not my purpose, to document in detail the pervasive hold of this attitude on various forms of political inquiry, but it ultimately results in the view that such inquiry is largely a form of mind-reading. Historians of political theory, as philosophically and methodologically diverse in some ways as Leo Strauss and Quentin Skinner, remain captured by the assumption that their subject matter is basically a history of thought, and they have been committed to recovering the ideas behind the texts of the classic canon. Strauss attempted, by a careful scrutiny of a text, to decipher the "intention," "purpose," and real meaning of an author such as Machiavelli (e.g., 1957). Despite Skinner's formidable challenge to certain aspects of Strauss's work, and to the traditional study of the history of political theory as a whole, he explicitly remained indebted to the idealist premises of Robin George Collingwood. He claimed that the task of the historian is to recover, by a detailed examination of the historical context of political language, what he referred to as, the "mentalities," that is, the "mental world" expressed in texts and political action (e.g., 1969, 1972).

Similarly, most political scientists assume mental causation action and that "beliefs," "attitudes," "preferences," and related constituents of our vocabulary refer to states of mind, which, even if not directly known, can be detected in, and inferred from, behavioral and linguistic markers and, at least operationally, defined. While some political theorists have periodically challenged the empiricism of mainstream political science and embraced what they conceive as more interpretive and qualitative modes of inquiry, such as that associated with the work of someone such as Charles Taylor (1971), they share the same underlying epistemological premises as those they criticize. Both camps assume that the task of interpretation, as defended by the literary critic Eric Donald Hirsch Jr., is to recover from objectified "intentional acts" an "original meaning" located in the "contents of mind" (1976).

The core of this dualistic image is the assumption that thought is ontologically autonomous and prior to language. Although the origins of this theory can be attributed to the work of Plato and Aristotle, it was formalized by Descartes 
and John Locke, passed on in the nineteenth century to both empiricism and idealism, and has remained influential. Although Locke, who is often deemed the classic empiricist, maintained that what he referred to as simple "ideas" originated from experiencing the external world, he argued that all we actually directly know are these ideas, which gain identity and meaning as representations in the "mind" and which are then expressed in language and social behavior. Bishop Berkeley, however, simply drew the logical conclusion that was immanent in empiricism, that is, that the experienced world is really just one of ideas. Kant tempered Berkeley's radical idealism by positing an invisible noumenal reality that was reflected in phenomenal experience, but he claimed that such experience ultimately gained meaning by the imposition of innate categories of the mind. As much as Marx may have ostensibly rebelled against Hegel and German idealism, and insisted that ideas are reflections of material conditions, he not only remained as vague as Locke about exactly how experience of the external world was translated into ideas, but also he claimed that ideology was the immediate explanation of human action and historical change.

In contemporary philosophy, this basic picture of the relationship between thought and language/action is reflected and reinforced in a variety of literature, including H.P. Grice's influential intention-based semantics and account of the primacy of "non-natural' or psychological meaning (1982); John Searle's argument that although the mind is an emergent property of the brain, it is autonomous and that the intentionality of language is a secondary manifestation of the mind's original "intrinsic" mental intentionality (1992); Noam Chomsky's Cartesian linguistics assuming that humans are endowed with an abstract mental super-grammar containing a basic syntactic and semantic structure, which underlies and allows the acquisition of a natural language; and related arguments such as those of Jerry Fodor (1975) and Steven Pinker (2007) who both claim that there is a primal innate and universal language of thought or what they refer to as "mentalese," which is composed of mental representations. The mind-first stance might appear to be contradicted by some philosophers and social theorists who have joined cognitive neuro-scientists in rejecting "folk psychology" as well as the philosophical dualism that has been referred to as "Descartes's error" (1994). But although they have propagated the claim that it is actually the brain that is the site of conscious and unconscious thought and judgment, their argument remains inflected with the same dualistic idiom. The brain has simply become the last refuge of an occult image of the mind. In all these cases, however, concepts are assumed to be the basic constituents of thought.

The term "concept" first appeared in the mid-sixteenth century, and, from the beginning, it has been prominently identified with mental phenomena. Although Locke did not actually use the word, he spoke about the clear and dist- 
inctive perception of an idea, generated by experience of the external world, as an "appearance or conception in the mind," which could then be mentally manipulated, made more complex, and expressed in language. Although it is generally agreed that in some manner concepts are mental phenomena, there have been various views about exactly how they relate to language. The influential philosopher Gottlob Frege (1848-1925) defined concepts as abstract objects of thought, which he referred to as "senses," that mediate between language and the specific objects to which language is applied. The general assumption, however, is that language is a vehicle for expressing concepts, and standard dictionaries continue to define a concept as a "thought," "something conceived in the mind," "a notion," or an "abstract or generic idea." But what constitutes a mind, a thought, or an idea, let alone a notion, is even more difficult to specify than the meaning of "concept." We do not have much difficulty identifying what kind of things words are, because words are physical signs and elements of language, which are used in various ways to say and do certain things. But concepts continue to seem anomalous. Despite the persistence of the mind-first attitude, it has been challenged in significant elements of twentieth century philosophy, and this challenge has important implications for how we should approach the study of concepts.

\section{The Critique of Mentalism}

The critique of mentalism was a central dimension of the later work of Ludwig Wittgenstein. He significantly began the Philosophical Investigations with a quotation from St. Augustine in which Augustine gave an account of how, as a child, he had learned the meaning of words by correlating the "sound" that adults made with the "thing" to which they "meant" to "point." Augustine claimed that he had been able to understand their "intentions" by observing the "bodily movements" that expressed their "state of mind." He said that by hearing words and locating them in sentences, he had also learned to form those same "signs" in order to "express" the thoughts that had heretofore been imprisoned within his mind (Wittgenstein, 2009, p. 1). For Wittgenstein, this account distorted both the processes actually involved in the human acquisition of language and in the capacity to understand others. This passage is usually, and correctly, interpreted as pointing to Wittgenstein's rejection of the universality of the object-designation theory of meaning and to his insistence that most words gain meaning by the manner in which they are used. What led him to this general conclusion, however, which is one of the core claims in the lectures recorded in the Blue and Brown Books and a basic theme of the Investigations, was his realization that although 
much of our mental terminology has many uses, it does not have any particular referential meaning. His famous extended critique of the image of a "private language" was a rejection of the assumption that there is any such thing as a language of thought that is different in kind from public languages. Despite what can reasonably be interpreted as some important differences between philosophers such as Gilbert Ryle (1949); Wilfrid Sellars (1956); J.L. Austin (1962); Richard Rorty (1979); Hilary Putnam (1999), and Donald Davidson (2001), they have, in important respects, followed or paralleled Wittgenstein's analysis.

The critics of mentalism all maintain that we can make sense of our mental vocabulary without the traditional theory of mind. Davidson, for example, emphasized that a term such as "belief" does not refer to a mental object but typically to the claims that a person holds to be true. They argue that although language is used to express thoughts, human thought and language have the same content and, both logically and historically, language preceded what we identify as thinking. Davidson claims that language is a condition of thought, and he rejected what he referred to as the "myth of the subjective." What he designated as "propositional attitudes" (believing, desiring, hoping, etc.), which he claimed constitute the content of thinking, are modeled on language, and he argued that thinking is like "silent utterances" and that "thought is essentially social" and requires the "gift of tongues" and "participation in a speech community." None of this is a denial of the existence of mental episodes but only the recognition that these are basically linguistic episodes. The upshot is that in order to understand the nature of concepts, we should be looking at language usage rather than assuming mysterious mental phenomena that supposedly lie behind language.

Wittgenstein stressed that not only are many concepts "vague," but that "concept' is a vague concept" and that "the word 'concept' is by far too vague" (Wittgenstein, 1978, p. 412). Although in the Investigations, he never explicitly disambiguated the meaning of "concept," he had once in the Tractatus, and occasionally in later work, employed the term "concept-word" (Begriffswort), which was largely identical to what he would subsequently simply refer to as a "concept." Ryle pointedly claimed that it is "not true that in any natural sense 'there are concepts,"' that is, such specific things, and that 'concept' is a term that refers to classes of word usage. He argued that while philosophers often conceive of themselves as clarifying concepts, this is just a "gaseous way of saying" that they are attempting, but often vainly, to specify a definitive substantive meaning for "general terms," that is, for words such as "justice" or "authority" (Ryle, 1932, p. 140).

The word "concept" is a term for referring to types of words. But although we often use an individual word to name a concept, "word" is not merely a synonym for "concept." Many words are not concept-words, more than one word 
can refer to the same thing, and different things may be referred to by the same word. When Wittgenstein said that if someone did not understand a "concept," he could teach them to use the "words," he was indicating that although words and concepts are not the same, they are related, because "when language games change, then there is a change in concepts, and with the concepts the meaning of words change" (Wittgenstein, 2009, p. 8; Wittgenstein, 1969, p. 65). To say that people possess and deploy concepts means that they have the ability to use a concept-word intelligibly.

\section{Political Science and the Treatment of Concepts}

Political scientists and political theorists often find themselves all tangled up in their discussion of concepts and the use of words such as "power," "state," "equality," and "justice." Some of the confusion is the consequence of not distinguishing between concept-words that refer to specific things and those that refer to kinds or categories of things, but what often creeps into discussions of concepts is a tendency to reify general terms and assume a Platonic image of concepts as abstract mental objects, which have particular empirical manifestations. A word such as "equality," for example, is a general term that has gained its meaning from positing similarities among particular things, but the instances are not tokens of some transcendent form or idea of equality. Confusion also sometimes arises from not distinguishing between words and the concepts to which some words refer. Many books are written about the history of a particular concept, such as, for example, the state or liberalism, when what such a book is often really about is a history of the word "state" or "liberalism" and the different, and sometimes incommensurable, things or concepts to which the word has been applied.

When social theorists analyze a concept such as representation or power, they often approach it as if they were talking about an abstract complex mental object composed of various aspects that can consequently be viewed and defined from various perspectives. They suggest that if all aspects of this object are accounted for, we can gain a complete account of the concept. In her influential book on the concept of representation, Hanna Pitkin treated representation in this manner (1967), but, in a later edition (1972), she stated, in a footnote, that after reading Wittgenstein, she had come to realize that her analysis was in some respects "profoundly misleading about concepts and language" (Pitkin, 1972/1967, p. 255). Although she neither revised her account in the later edition nor specified why it was so misleading, it was misleading because there actually is no such thing as "the" concept of representation that lies behind various uses of the word. Steven Lukes, among others, has talked about the different "faces" 
of power, as if power were a distinct object, which could be described in various terms (1974). "Power," however, like "representation," is a word used to refer to a variety of things that are often viewed in some manner, and according to some criterion, as similar.

While some theorists, such as Pitkin and Lukes, assume that the problem of understanding concepts resides in their complex, an equally common but related, and probably even more pervasive, mistake has been to claim that the problem is somehow located in the very nature of concepts, or at least certain concepts. The argument is that concepts such as representation, democracy, or power are difficult to deal with because their meaning is in some way necessarily inconclusive or indeterminate. It is argued that this is especially a problem with normative concepts such as justice. The classic statement of this position was the essay by the philosopher Walter Bryce Gallie (1956) on "essentially contested concepts," which has been a continuing source of both hope and confusion among political theorists and political scientists. Gallie claimed to be isolating certain concepts, such as democracy, which, he argued, have a number of distinctive intrinsic attributes, which together necessarily give rise to disputes about their genuine meaning when, in fact, the very nature of such concepts prevents any determination of uncontested meaning.

For many political theorists, Gallie's argument has been appealing. It seemed to provide insight into the conflictual character of politics and political discourse as well as the multiple perspectives that often inform social scientific approaches to politics. It appeared particularly useful to those who rejected behavioral methods and insisted that political inquiry is an interpretive endeavor and who were wary of the attempts of some social scientists to construct the kind of precise definitions that seemed to characterize the natural sciences. Gallie's formulation has explicitly found its way into many discussions of political and legal analysis (e.g., Freeden, 2008; Collier, Hidalgo, and Maciuceanu, 2006; Mason, 1990; Grafstein,1988; Koselleck, 2002; Swanton, 1985; Rawls, 1971; Dworkin, 1972).

An early major proponent of this position was Alasdair MacIntyre (1973) who argued that a basic difference between natural science and social science is the "open texture" of the concepts both employed and studied by social scientists, which entails an "essential incompleteness" and "essential contestability" that cannot be solved by definitions and other such strategies. What many political theorists, such as William Connolly (1993), took from Gallie was not only what they saw as an explanation of the peculiarities of the "terms of political discourse," which made political inquiry so different from the methodology of natural science, but a justification for what they defended as the inherently pluralistic character of politics. The response to the kind of argument that Gallie advanced was often, as in the case of individuals such as Giovanni Sartori (1984), 
as well as Theodore Lowi and Mario Calise (2011), to call for a yet greater reduction in terminological fluidity and debate. Some, however, such as Jeremy Waldron (2002), have defended and accentuated Gallie's basic claim and argued that Gallie's radical point about the necessary indeterminacy of certain concepts has been neglected and mistakenly interpreted as the weaker claim that the use of some concepts is often disputed and not well-defined.

The recent infatuation with applying research in cognitive science to the study of politics is an example of the perennial search for a biological or physiological foundation for social scientific inquiry, and this has influenced the treatment of concepts. George Lakoff (2008) attempted to explain essentially contested concepts in terms of what he claimed was experimental evidence indicating that concepts are instantiated in the synapses of the brain and arise from an interaction between the mind/brain and world. Although it might be reasonable to suggest that there is an interaction between the brain and the world, Lakoff did not actually explain how this gives rise to concepts or how they can be conceived as located in the brain.

There is simply no such thing as an essentially contested or indeterminate concept, and even if Gallie had actually been referring to words, which he often seemed to imply, he would have been incorrect in claiming that some words are essentially contested. What might be construed as the underlying issue in an analysis such as that of Pitkin or Lukes, as well as in arguments about essential contestability, have been what a number of theorists have claimed to be the difference between the core meaning of a concept, such as justice, law, power, and so on, and derivative conceptions of these concepts. Rawls argued that it is possible to discern a common content to the concept of justice, which he designated as fairness, but that there are contested specifications or conceptions of what constitutes fairness - utilitarian, egalitarian, etc. Dworkin also claimed that we can isolate a general concept of fairness but that there are different "conceptions" of what it entails. One problem with these claims is that "conception," which the dictionary also refers to "something conceived in the mind," is not easily distinguished from, or made more transparent in meaning, than "concept." In addition to the theoretical problems inherent in the mind-first approach to concepts is that it distracts us from the very phenomena that we wish to understand, that is, from the texts and action where meaning actually resides rather than in hypothetical mentalities.

The practical difficulties also often involve a failure to distinguish between different kinds of concepts or concept-words. It is important not to confuse these kinds or use one kind as a paradigm for assessing another kind. Although it might be possible to construct an extended taxonomy of concept-words, there are four kinds that are particularly salient in both political discourse and in social inquiry and which deserve special attention. 


\section{Concept Words}

What I will designate as theoretical concept-words appear in natural science as well as in other relatively determinate linguistic communities, ranging from religion and science to the commonsense visions of the world inherent in various cultures, that are bound together by assumptions and claims about what kinds of things exist and the manner of their existence. Theoretical concepts may appear as similar to everyday empirical claims with set standards of truth-value relating to what they represent, but theoretical claims actually represent nothing. They are instead the framework within which representation takes place and within which facts represented gain identity. It would more accurate to say that natural science, at the theoretical level, presents the world. The word "representation" usually is used in a manner that presupposes a prior and autonomous object. After natural science, or some other authoritative discourse provides an account of the world and our place in that world, it is not possible to check that account by comparing it with some transcendental image of the world but only with some other comparable but incommensurable account either within science or another theoretical domain. Theoretical transformations are, as both Wittgenstein claimed in On Certainty (1969) and Thomas Kuhn (1970) detailed, ultimately a matter of persuasion and conversion.

Although social science is in one respect presentational in that it also involves theoretical assumptions and claims about the nature of social phenomena, it is basically a representational enterprise. No matter how social phenomena are construed by social science, they have been theoretically pre-constituted in the speech and behavior of social actors, and the task of social inquiry is to understand, interpret, and represent such discursive phenomena. Consequently, the fundamental problem of social science is to find an appropriate language of representation that can adequately account for and clarify the meaning of social facts but also avoid reification or confusing the language of representation with what is represented. The latter may be the most significant problem in social inquiry, as Wittgenstein so often pointed out with respect to philosophy, which he basically viewed as a form of social inquiry, and, even earlier, Max Weber had made a similar argument in his discussion of ideal-types.

Categorical concept-words are those that, on the basis of various criteria, either internal to a domain of discourse or externally generated by an interpreter of that domain, are used to discriminate and classify things that have often already been theoretically specified. With respect to natural science, for example, we might say that in physics, atoms and molecules, and the distinctions between them, represent theoretical kinds, while the classification of bees is basically categorical or taxonomic. Categorical concept-words are particularly 
prevalent and necessary in fields such as social science and history, which are confronted with the problem of representing historical and cultural particulars, which do not lend themselves to theoretical amalgamation but which may usefully be construed in various ways as similar. Projects designed to achieve precise definitions of social facts ultimately fail because of the variable and changing character of social phenomena, but despite the particularity of such phenomena, there is still a need for generalization. This kind of problem was what led to formulations such as Weber's ideal-types and to Wittgenstein's emphasis on a philosophical method that involved the invention of fictitious "language-games" that would yield "perspicuous representations" (Wittgenstein, 2009) and would reconcile the reality of particularity with the concern for generality. In the case of social science, there is both the problem of understanding and interpreting the concept-words that are indigenous to social phenomena and the problem of formulating a language for accomplishing that task. And there is a persistent mistake of seeking representational hegemony by universalizing one mode of representation and attempting to achieve methodological unity, such as in the case of systems analysis in the 1960s or the later rise of rational choice analysis.

Social scientists also typically employ a number of analytical concepts-words. These are in many ways like categorical ones and, like the latter, easy to mistake for theoretical concept-words. But they are even more arbitrary than categories. They construct or carve out a domain that is composed, on the basis of chosen criteria, of various elements. The elements of an analytical construct are not the same as parts of a whole but more like the elements of logical set. David Easton (1965) claimed that what he meant by a political system was a matter of analytically factoring out particulars and constructing a scheme that might have no empirical counterpart. He argued that even "a duckbilled platypus and the ace of spades" could be construed as a system, if it were, in some manner, useful as a tool of analysis (Easton, 1965, p. 33).

Social inquiry not only deals with values as social phenomena but often wishes to engage in evaluative and prescription claims about such phenomena, and this brings us to what I will refer to as modal concept-words on which value claims are predicated. These include good, beautiful, true, real, rational, probable, and so on and are involved in arguments such as those of Rawls and Dworkin, which employ words such as "justice" and "right." Unlike theoretical terms, they do not carry with them any necessary ontological commitments and are not confined to a particular practice or form of discourse. Although, as Stephen Toulmin (1958) pointed out, they may, through usage, tend to acquire a certain conventional invariant element of meaning, their criteria of application are relative to particular practices and language communities and are what Austin spoke 
of as "substantive hungry" (1962). This sometimes creates the illusion of essential contestability, but it is not their basic meaning or use that is disputed but the criteria of their use. The presence of a modal term, such as "good," in a sentence does not even necessarily indicate or dictate that the sentence is, for example, evaluative or prescriptive, but the residual force attaching to "good" is a consequence of its past use in such sentences. A problem with arguments such as those of Rawls or Dworkin is that they tend to couch their discussions in a language that suggests that they are making a discovery about justice or rights when in fact they are making an argument about what should be conceived as "just' or "right" and consequently how these words should be applied. Such words, like theoretical concept-words, are often used in presentational claims about what is right, just, true, or beautiful, which, like theoretical claims, cannot be compared with the world because they are constitutive of an ethical, religious, and aesthetic account of some dimension of the world.

\section{The Concept of the Political}

Any study of politics must come to grips with the problems of specifying the units and boundaries of what we take to be a political domain and of how to represent that domain. There are all sorts of ways to do this, and maybe the greatest problem is not so much determining a correct way but distinguishing between, and not confusing, these ways. So the relevant question is that of what, exactly, is the realm we call politics?

During the twentieth century, Carl Schmitt, Leo Strauss (1932), Reinhart Koselleck (2002), Hannah Arendt (1958), Sheldon Wolin (1960) as well as many others (e.g., Mouffe, 1996; Freeden, 2013) who have often been influenced by their work or similar arguments, appeared to confer a quasi-ontological or theoretical status on politics. This led to the transformation of the adjective "political" into a noun-phrase, that is, to treat it as if it were a concept-word that named a thing that was in some way assumed to be universal despite differences between, and changes, in its particular manifestations. For these individuals, "the political" was something transcendentally real, which manifested itself historically from time to time. But it was often viewed as less than fully realized and in danger of being effaced, as, for example, Arendt so dramatically portrayed in the Human Condition (1958). This image was eventually adopted by a wide range of ideologically and epistemologically diverse strands of political theory.

Politics, however, does not have a nature or essence any more than any other conventional social practice. "Politics," in the first instance, refers to a specific historical, evolving, dispersed, but socially and culturally circumscribed, particu- 
lar form of human life, which arguably had a beginning and will possibly have an end as a conventionally discriminated element of social organization. Other uses of "politics" are necessarily derivative and metaphorical. Part of the problem with the word "politics" stems from the fact that it is both a concept in political discourse and a term for describing political life, and there is a problem of how to reconcile the two. Political practices do not stand still for those who wish to define and analyze politics. Observations of politics can yield claims about family-resemblances among historical and cultural instances of political practice, but noting such similarities, does not achieve the goal that is often being sought through these definitions, that is, the equivalent of some ur-phenomenon of which these putative instances of politics are manifestations.

There is, then, no simple and general answer to the question of how to approach representing politics, but it is important not to allow slippage between, on the one hand, a metaphorical or figurative use of "politics" or a categorical/ analytical concept of politics and, on the other hand, the use of "politics" to refer to a particular and historically situated practice. In representing and conveying the meaning of social phenomena, we have little choice in choosing our vocabulary. We are bound either to something drawn from our familiar vernacular or to an invented formalism, but in both cases, there is the danger of reification, as in the case of political scientists who maintained that locating something such as relationships of power in a society was equivalent to identifying the existence of politics.

There are various complex philosophical and ideological motivations behind the emergence of essentialist notions of politics and claims about the ontology of "the political," but there is a danger of overlooking the logical type-jump that is involved in moving from claims about politics, as a specific historically and culturally situated practice, to a general definition. This was the kind of problem that Weber wanted to avoid when he stressed the need not to limit inquiry to one "ideal-type" and that Wittgenstein was addressing when he advocated inventing a variety of "perspicuous representations," which would be adapted to capturing and conveying the meaning of particular practices. In the attempt to generalize functionally, analytically, or categorically in a manner that finds politics everywhere, we may end up finding that it is nowhere. Something that looks like politics, acts like politics, talks like politics, and about which it may in some sense be useful to talk about as if politics, may not, unlike the case of the proverbial duck, really be politics at all. 


\section{References}

Arendt, H. (1958). The Human Condition. Chicago: University of Chicago Press.

Austin, J.L. (1962). Sense and Sensibilia. Oxford: Oxford University Press.

Collier, D., Hidalgo, D.F., Maciuceanu, A.O. (2006). "Essentially Contested Concepts: Debates and Applications". Journal of political Ideologies, 2, pp. 211-246.

Connolly, W. (1993/1974). The Terms of Political Discourse. New York: Wiley-Blackwell.

Damasio, A. (1994). Descartes' Error: Emotion, Reason, and the Human Brain. New York: Putnam's Sons.

Davidson, D. (2001). Subjective, Intersubjective, and Objective. Oxford: Oxford University Press.

Dworkin, R. (1972). “The Jurisprudence of Richard Nixon”. New York Review of Books, 18 , pp. 27-35.

Easton, D. (1953). The Political System. New York: Knopf.

Easton, D. (1965). A Framework for Political Analysis. Englewood Cliffs, NJ: Prentice-Hall. Fodor, J. (1975). The Language of Thought. Cambridge, MA: Harvard University Press.

Freeden, M. (2008). Ideologies and Political Theory: A Conceptual Approach. Oxford: Clarendon Press.

Freeden, M. (2013). The Political Theory of Political Thinking: The Anatomy of a Practice. Oxford: Oxford University Press.

Gallie, W.B. (1956). "Essentially Contested Concepts”. Proceedings of the Aristotelian Society, 56, pp. 167-198.

Goertz, G. (2005). Social Scientific Concepts: A User's Guide. Princeton: Princeton University Press.

Grafstein, R. (1988). “A Realist Foundation for Essentially Contested Concepts”. Western Political Quarterly, 41, pp. 9-28.

Grice, H.P. (1982). “Meaning Revisited”. In: V. Smith (ed.). Mutual Knowledge, New York: Academic Press.

Hirsch, E.D. (1976). The Aims of Interpretation. Chicago: University of Chicago Press.

Koselleck, R. (2002). The Practice of Conceptual History: Timing History, Spacing Concepts. Stanford: Stanford University Press.

Kuhn, T. (1970). The Structure of Scientific Revolutions, $2^{\text {nd }}$ ed. Chicago: University of Chicago Press.

Lakoff, G. (2008). The Political Mind: A Cognitive Scientist's Guide to Your Brain and Politics. New York: Penguin.

Lowi, T., Calise, M. (2011). Hyperpolitics: An Interactive Dictionary of Political Science Concepts. Chicago: University of Chicago Press.

Lukes, S. (1974). Power: A Radical View. New York: Macmillan.

MacIntyre, A. (1973). “The Essential Contestability of Some Social Concepts”. Ethics, 84, pp. 1-9. 
Mason, A. (1990). "Explaining Political Disagreement: The Notion of an Essentially Contested Concept". Inquiry, 33, pp. 81-98.

Mouffe, Ch. (1996). "Deconstruction, Pragmatism, and the Politics of Democracy". In: Ch. Mouffe (ed.). Deconstruction and Pragmatism. Deconstruction, Pragmatism, and the Politics of Democracy. London: Routledge.

Pinker, S. (2007). The Stuff of Thought: Language as a Window into Human Nature. New York: Penguin.

Pitkin, H. (1972/1967). The Concept of Representation. Berkeley: University of California Press.

Political Concepts: A Critical Lexicon, http://www.politicalconcepts.org/ (accessed: 7.04.2017).

Putnam, H. (1999). The Three-Fold Cord: Mind, Body, and World. New York: Columbia University Press.

Radaelli, C.M. (2000). "Whether Europeanization: Concept Stretching and Substantive Change". European Integration, online papers, 4:\#8.

Rawls, J. (1971). A Theory of Justice. Cambridge: Harvard University Press.

Rorty, R. (1979). Philosophy and the Mirror of Nature. Princeton: Princeton University Press.

Ryle, G. (1932). "Systematically Misleading Expressions”. Proceedings of the Aristotelian Society, 32.

Ryle, G. (1949). The Concept of Mind. London: Hutchinson.

Sartori, G. (1970). “Concept Formation in Comparative Politics”. American Political Science Review, 64, pp. 1033-1053.

Sartori, G. (1984). Social Science Concepts: A Systematic Analysis. London: Sage Publications.

Searle, J. (1992). The Rediscovery of the Mind. Cambridge, MA: MIT Press.

Sellars, W. (1956). "Empiricism and the Philosophy of Mind". In: H. Feigl, M. Scriven (eds.). Minnesota Studies in the Philosophy of Science, Vol. 1: The Foundations of Science the Concepts of Psychology and Psychoanalysis (pp. 253-329). Minneapolis: University of Minnesota Press.

Skinner, Q. (1969). "Meaning and Understanding in the History of Ideas". History and Theory, 8, pp. 3-53.

Skinner, Q. (1972). “Motives, Intentions, and the Interpretation of Texts”. New Literary History, 3, pp. 400-407.

Strauss, L. (1932). "Notes on Carl Schmitt, The Concept of the Political". Archiv für Sozialwissenschaft und Sozialpolitik, Vol. 67, No. 6.

Strauss, L. (1957). "Machiavelli’s Intention: The Prince". American Political Science Review, 51, pp. 13-40.

Swanton, Ch. (1985). “On the Essential Contestedness of Political Concepts”. Ethics, 95, pp. 811-827. 
Taylor, Ch. (1971). "Interpretation and the Sciences of Man". Review of Metaphysics, 25(1), pp. 3-51.

Toulmin, S. (1958). The Uses of Argument. Cambridge: Cambridge University Press.

Waldron, J. (1989). "Rights in Conflict”. Ethics, 99, pp. 503-519.

Waldron, J. (2002). "Is the Rule of Law An Essentially Contested Concept (In Florida)?". Law and Philosophy, 21, pp. 137-164.

Wittgenstein, L. (1969). On Certainty. Oxford: Blackwell.

Wittgenstein, L. (1978). Remarks on the Foundations of Mathematics. Oxford: Blackwell. Wittgenstein, L. (2009). Philosophical Investigations, P.M.S. Hacker, J. Schulte (eds.). Oxford: Blackwell.

Wolin, S.S. (1960). Politics and Vision. Boston: Little, Brown. 